\title{
FAKTOR YANG MEMPENGARUHI IBU DALAM KUNJUNGAN IMUNISASI PADA MASA PANDEMI COVID-19 DALAM PERSPEKTIF HEALTH BELIEF MODEL (HBM)
}

\author{
Nani Susilowati ${ }^{1}$, Titik Sapartinah ${ }^{2}$, Erna Widyastuti ${ }^{3}$ \\ 1,2,3Jurusan Kebidanan, Poltekkes Kemenkes Semarang, Indonesia
}

\begin{abstract}
Pandemic Covid-19 has an impact on the implementation of health programs, especially immunization services and PD3I surveillance. Coverage of immunization at Kaliwungu health center is still low, especially polio (89.3\%) compared to 23 other health centers in Semarang regency and immunization visits only 3.2\% in March. The purpose of the study was to determine the factors that influenced immunization visits during the Covid-19 pandemic period based on the health belief model (HBM) theory at Kaliwungu health center. This research is observational analytic research with a maternal population who has a baby aged 1-12 months, a total of 370 people and a sample of 80 people. The results of the univariate analysis of the Chi Square test of vulnerability and high seriousness $51.2 \%$, perception of cues to action high 58.8\%, high benefit perception of $72.5 \%$, high barrier perception of $46.3 \%$, and active immunization visits $66.3 \%$, Bivariate analysis of perception of vulnerability and seriousness ( $p$ value 0.001), perception of benefits ( $p$ value 0.009), perception of barriers ( $p$ value 0.009) and perception cues to action ( $p$ value 0.169 ). The conclusion of the study is that there is a relationship between the vulnerability and seriousness of the disease, benefits and obstacles with immunization visits. While the perception of cues to action has no relationship with immunization visits during the Pandemic Covid-19 period. Advice for health workers to improve information services and immunization health promotion during Covid-19.
\end{abstract}

Keywords: Immunization Visit; Covid-19 Pandemic 


\section{PENDAHULUAN}

Imunisasi dapat menjadi salah satu cara untuk memperkuat kekebalan tubuh terhadap penyakit, sehingga apabila terjangkit penyakit, tubuh tidak akan menderita penyakit tersebut karena sudah memiliki sistem memori (Mulyani, 2013). Covid-19 yang terjadi secara global mempengaruhi pelaksanaan program kesehatan khususnya pelayanan imunisasi dasar dan surveilans PD3I. berdasarkan informasi yang didapat, menyebutkan bahwa setidaknya 80 juta anak usia kurang dari 1 tahun memiliki resiko untuk menderita penyakit difteri, campak dan polio akibat terganggunya pelayanan imunisasi rutin di tengah pandemi Covid-19. Terdapat 64\% dari 107 negara mengalami gangguan atau keterlambatan dalam pelaksanaan pelayanan imunisasi rutin (Direktur Jenderal Pencegahan dan Pengendalian Penyakit Kemenkes RI, 2020).

Adanya Covid-19 di Indonesia menurunkan cakupan imunisasi rutin untuk mengantisipasi penyakit seperti campak, rubella, dan difteri pada anak. Misalnya, angka cakupan imunisasi difteri, pertusis dan tetanus (DPT 3) dan rubella (MR 1) turun 35\% di bulan mei 2020 dibandingkan pada tahun lalu. Sekitar $50 \%$ responden dari hasil survei tidak pergi ke fasilitas pelayanan imunisasi disebabkan oleh pandemi (Kemenkes RI \& UNICEF, 2020).
Berdasarkan data Dinkes Kab. Semarang, (2020), cakupan imunisasi masih rendah diantara 26 puskesmas di Kabupaten Semarang, dengan cakupan imunisasi polio 4 sebesar $89,3 \%$ dengan jumlah persentase bayi berdasarkan jenis kelamin laki-laki sebanyak 77,3\%, sedangkan perempuan 104\%. Berdasarkan data studi pendahuluan kunjungan imunisasi lengkap pada bulan Maret sampai Desember, bulan Maret mengalami penurunan signifikan jika dibandingkan bulan sebelumnya, yaitu hanya sebesar $3,2 \%$. Sedangkan data cakupan imunisasi bulan April sampai bulan Desember mengalami peningkatan dengan persentase dari 5.5\%-17,8\% namun mengalami penurunan drastis kembali pada bulan November dengan persentase $5,3 \%$.

Menurut Novianda \& Mochammad (2020) faktor yang mempengaruhi pemenuhan imunisasi dasar adalah sikap, kepercayaan, dukungan keluarga, akses, dan informasi.Teori Health Belief Model (HBM) menurut Rosenstock dalam Sarwono, (2007) mencakup komponen utama yaitu: kerentanan yang dirasakan (perceived susceptibility), keseriusan yang dirasakan (perceived seriousness), ancaman penyakit yang dirasakan (perceived threat of disease), manfaat dan rintangan yang dirasakan (perceived benefits barriers), dan faktor cues to action. Berdasarkan latar belakang di atas maka dilakukanya penelitian yang berjudul Faktor Yang Mempengaruhi Ibu Dalam 
Kunjungan Imunisasi Pada Masa Pandemi Covid-19 dalam Perspektif Health Belief Model (HBM).

\section{METODOLOGI PENELITIAN}

Penelitian ini menggunakan jenis dan desain penelitian analitik observasional dengan pendekatan cross sectional. Populasi berjumlah 370, yang merupakan seluruh ibu yang memiliki bayi usia 1-12 bulan di Puskesmas Kaliwungu dan sampel berjumlah 80 responden diambil dengan teknik simple random sampling. Sumber data penelitian ini yaitu data primer yang didapat langsung dengan cara menyebarkan kuesioner kepada responden di Puskesmas Kaliwungu. Data kemudian dianalisis berdasarkan frekuensi dan Analisa bivariat menggunakan uji statistik Chi-Square.

\section{HASIL PENELITIAN DAN BAHASAN}

Tabel.1Distribusi Responden Berdasarkan Persepsi Kerentanan Keseriusan, Cues to Action, Manfaat dan Hambatan dalam Melakukan Kunjungan Imunisasi pada Masa Pandemi Covid-19.

\begin{tabular}{clcc}
\hline Variabel & Kategori & Frekuensi & $\begin{array}{c}\text { Presentase } \\
(\%)\end{array}$ \\
\hline \begin{tabular}{c} 
Kerentanan $\begin{array}{c}\text { Nan } \\
\text { dan } \\
\text { Keseriusan }\end{array}$ \\
\cline { 2 - 4 }
\end{tabular} & Tinggi & 41 & 51,2 \\
\hline & Jendah & 39 & 48,8 \\
\hline $\begin{array}{c}\text { Cues To } \\
\text { Action }\end{array}$ & Tinggi & 47 & 58,8 \\
\cline { 2 - 4 } & Rendah & 33 & 41,3 \\
\hline & JUMLAH & 80 & \\
\hline Manfaat & Tinggi & 58 & 72,5 \\
\cline { 2 - 4 } & Rendah & 22 & 27,5 \\
\hline & JUMLAH & 80 & \\
\hline
\end{tabular}

\begin{tabular}{clll}
\hline Hambatan & Tinggi & 37 & 46,3 \\
\cline { 2 - 4 } & Rendah & 43 & 53,8 \\
\hline & JUMLAH & 80 & \\
\hline Kunjungan & Aktif & 53 & 66,3 \\
\cline { 2 - 4 } $\begin{array}{c}\text { Imunisasi } \\
\text { Dasar }\end{array}$ & Tidak & 27 & 33,8 \\
\hline & Aktif & & \\
\hline & JUMLAH & 80 & \\
\hline
\end{tabular}

Pada tabel. 1 menunjukan data dari 80 responden yang diberikan pertanyaan mengenai persepsi kerentanan dan keseriusan penyakit tinggi, terdapat 41 responden $(51,2 \%)$ dan 47 responden (58,8\%) dengan persepsi cues to action tinggi. Kemudian, responden yang diberi pertanyaan persepsi manfaat, terdapat 58 responden $(72,5 \%)$ dengan persepsi tinggi, persepsi hambatan terdapat 37 responden (46,3\%) dengan hambatan tinggi dan persepsi kunjungan imunisasi dasar aktif ditengah pandemi Covid-19 sebanyak 53 responden $(66,3 \%)$

Tabel.2 Hubungan Persepsi Kerentanan dan Keseriusan dengan Kunjungan Imunisasi Masa Pandemi Covid-19

\begin{tabular}{|c|c|c|c|c|c|c|c|}
\hline \multirow{3}{*}{$\begin{array}{c}\text { Persepsi } \\
\text { Kerentanan } \\
\text { \&Keseriusan } \\
\text { Penyakit }\end{array}$} & \multicolumn{4}{|c|}{$\begin{array}{c}\text { Kunjungan Imunisasi } \\
\text { Dasar }\end{array}$} & \multirow{2}{*}{\multicolumn{2}{|c|}{ Total }} & \multirow[t]{3}{*}{$\begin{array}{c}P \\
\text { Value }\end{array}$} \\
\hline & \multicolumn{2}{|c|}{ Aktif } & \multicolumn{2}{|c|}{$\begin{array}{l}\text { Tidak } \\
\text { Aktif }\end{array}$} & & & \\
\hline & $\mathrm{n}$ & $\%$ & $\mathrm{n}$ & $\%$ & $\mathrm{n}$ & $\%$ & \\
\hline Tinggi & 35 & 85,4 & 6 & 14,6 & 41 & 100 & 0,001 \\
\hline Rendah & 18 & 46,2 & 21 & 53,8 & 39 & 100 & \\
\hline Total & 53 & 66,3 & 27 & 33,8 & 80 & 100 & \\
\hline
\end{tabular}

Hasil penelitian tabel 2 menunjukan responden yang mempunyai persepsi kerentanan dan keseriusan penyakit tinggi, aktif dalam melakukan kunjungan imunisasi dasar di tengah pandemi Covid-19 sebanyak 35 responden $(85,4 \%)$ lebih banyak dari 
responden dengan persepsi kerentanan dan keseriusan rendah yang aktif kunjungan imunisasi sebanyak 18 responden $(46,2 \%)$.

Hasil uji chi-square didapatkan hasil $p$ value $0,001<\alpha(0,05)$ sehingga $\mathrm{Ha}$ diterima yang menyatakan ada hubungan persepsi kerentanan dan keseriusan penyakit terhadap kunjungan imunisasi dasar di tengah pandemi Covid-19 di Puskesmas Kaliwungu.

\section{Menurut Priyoto (2014) dalam}

Dewi et al., (2017) bahwa keyakinan atau kepercayaan individu berkaitan dengan seberapa serius dan parahnya suatu penyakit, dipengaruhi oleh informasi medis atau pengetahuan dan keyakinan seseorang mengenai kesulitan dan dampak yang akan didapat akibat penyakit tersebut. jika seorang ibu berpersepsi rentan terhadap suatu penyakit maka ibu tersebut akan mengambil berbagai tindakan pencegahan berbeda, termasuk melakukan imunisasi.

Tabel.3 Hubungan Persepsi Cues to Action dengan Kunjungan Imunisasi pada Masa Pandemi Covid-19

\begin{tabular}{|c|c|c|c|c|c|c|c|}
\hline \multirow{3}{*}{$\begin{array}{c}\text { Persepsi } \\
\text { Cues To } \\
\text { Action }\end{array}$} & \multicolumn{4}{|c|}{$\begin{array}{c}\text { Kunjungan Imunisasi } \\
\text { Dasar }\end{array}$} & \multirow{2}{*}{\multicolumn{2}{|c|}{ Total }} & \multirow[t]{3}{*}{$\begin{array}{c}P \\
\text { Value }\end{array}$} \\
\hline & \multicolumn{2}{|c|}{ Aktif } & \multicolumn{2}{|c|}{$\begin{array}{l}\text { Tidak } \\
\text { aktif }\end{array}$} & & & \\
\hline & $n$ & $\%$ & $n$ & $\%$ & $\mathrm{n}$ & $\%$ & \\
\hline Tinggi & 34 & 72,3 & 13 & 27,7 & 47 & 100 & 0,169 \\
\hline Rendah & 19 & 57,6 & 14 & 42,4 & 33 & 100 & \\
\hline Total & 53 & 66,3 & 27 & 33,8 & 80 & 100 & \\
\hline
\end{tabular}

Hasil penelitian tabel 3 menunjukan responden yang mempunyai persepsi cues to action tinggi, aktif melakukan kunjungan imunisasi di tengah pandemi Covid-19 sebanyak 34 responden (72,3\%) lebih banyak dibandingkan responden yang memiliki persepsi rendah yang aktif kunjungan imunisasi, sebanyak 19 responden (57,6\%).

Hasil uji chi-square didapatkan hasil $p$ value $0,169>\alpha(0,05)$, sehingga $\mathrm{Ha}$ ditolak yang menyatakan tidak ada hubungan persepsi kerentanan dan keseriusan penyakit terhadap kunjungan imunisasi dasar pada masa pandemi Covid-19 di Puskesmas Kaliwungu Kabupaten Semarang.

Tidak semua persepsi cues to action membuat seseorang melakukan tindakan, tidak menutup kemungkinan untuk ibu yang memiliki persepsi rendah memberikan imunisasi kepada anaknya pada masa pandemi, dikarenakan timbulnya prilaku terdapat faktor-faktor lain yang mempengaruhi. Menurut Ary, dkk (2012) dalam Islamiyah \& Fatah, (2019), penyebab ketidakpatuhan ibu dalam memenuhi imunisasi bayinya akibat adanya anjuran dari orang lain atau keluarga.

Tabel.4 Hubungan Persepsi Manfaat dengan Kunjungan Imunisasi Dasar pada Masa Pandemi Covid-19

\begin{tabular}{cccccccc}
\hline $\begin{array}{c}\text { Persepsi } \\
\text { Manfaat }\end{array}$ & \multicolumn{4}{c}{$\begin{array}{c}\text { Kunjungan Imunisasi } \\
\text { Dasar }\end{array}$} & Total & $\begin{array}{c}P \\
\text { Value }\end{array}$ \\
\cline { 2 - 6 } & \multicolumn{2}{c}{ Aktif } & \multicolumn{2}{c}{$\begin{array}{c}\text { Tidak } \\
\text { aktif }\end{array}$} & & \\
\cline { 2 - 7 } & $\mathrm{n}$ & $\%$ & $\mathrm{n}$ & $\%$ & $\mathrm{n}$ & $\%$ & \\
\hline Tinggi & 33 & 56,9 & 25 & 19,6 & 58 & 100 & 0,009 \\
\hline Rendah & 20 & 90,9 & 2 & 7,4 & 22 & 100 & \\
\hline Total & 53 & 66,3 & 27 & 33,8 & 80 & & \\
\hline
\end{tabular}


Hasil penelitian tabel 4 menunjukan responden yang mempunyai persepsi manfaat tinggi, aktif melakukan kunjungan imunisasi dasar di tengah pandemi Covid-19 yaitu 33 responden (56,9\%), lebih banyak daripada responden yang memiliki persepsi manfaat rendah yang aktif kunjungan imunisasi dasar, berjumlah 20 orang $(90,9 \%)$.

Hasil uji chi-square diperoleh $p$ value $0,009<\alpha(0,05)$, artinya $\mathrm{Ha}$ diterima, maka ada hubungan persepsi manfaat terhadap kunjungan imunisasi dasar di tengah pandemi Covid-19 di Puskesmas Kaliwungu. Menurut Puri et al., (2016) dalam penelitianya, juga menyatakan terdapat pengaruh positif secara langsung antara persepsi manfaat dengan kelengkapan imunisasi ( $p$ value $0,002)$.

Tabel.5 Hubungan Persepsi Hambatan dengan Kunjungan Imunisasi Dasar pada Masa Pandemi Covid-19

\begin{tabular}{cccccccc}
\hline $\begin{array}{c}\text { Persepsi } \\
\text { Hambatan }\end{array}$ & \multicolumn{2}{c}{ Kunjungan Imunisasi } & Total & $\begin{array}{c}P \\
\text { Value }\end{array}$ \\
\cline { 2 - 6 } & \multicolumn{4}{c}{$\begin{array}{c}\text { Tidak } \\
\text { aktif }\end{array}$} & & & \\
\cline { 2 - 7 } & $\mathrm{n}$ & $\%$ & $\mathrm{n}$ & $\%$ & $\mathrm{n}$ & $\%$ & 009 \\
\hline Tinggi & 19 & 51,4 & 18 & 48,6 & 37 & 100 & \\
\hline Rendah & 34 & 79,1 & 9 & 20,9 & 43 & 100 & \\
\hline Total & 53 & 66,3 & 27 & 33,8 & 80 & & \\
\hline
\end{tabular}

Hasil penelitian tabel 5 menunjukan responden yang memiliki persepsi manfaat tinggi, aktif melakukan kunjungan imunisasi dasar pada masa pandemi yaitu 19 responden $(51,4 \%)$ lebih sedikit daripada responden dengan persepsi hambatan rendah yang aktif kunjungan imunisasi sebanyak 34 responden $(79,1 \%)$. Hasil uji chi-square diperoleh $p$ value $0,009<\alpha(0,05)$, artinya Ha diterima, yang menyatakan terdapat hubungan persepsi hambatan dengan kunjungan imunisasi di masa pandemi Covid-19 di Puskesmas Kaliwungu.

Menurut Priyoto (2018) dalam Siswanto et al., (2020), persepsi hambatan yaitu kesulitan yang akan diperoleh saat memberikan imunisasi. Seseorang akan cenderung memberikan imunisasi pada anak jika manfaat yang dirasakan lebih tinggi daripada persepsi hambatan yang dialami.

\section{KESIMPULAN}

Sebagian besar ibu di wilayah kerja Puskesmas Kaliwungu memiliki persepsi kerentanan dan keseriusan penyakit tinggi $(51,2 \%)$, persepsi cues to action tinggi (58,8\%), persepsi manfaat tinggi $(72,5 \%)$, persepsi hambatan tinggi (46,3\%) dan aktif melakukan kunjungan imunisasi sebanyak 66,3\%. Terdapat hubungan yang bermakna antara persepsi kerentanan dan keseriusan, persepsi manfaat dan persepsi hambatan. Sedangkan persepsi cues to action tidak terdapat hubungan dengan kunjungan imunisasi dasar pada masa pandemi Covid-19 di Puskesmas Kaliwungu.

\section{UCAPAN TERIMAKASIH}

Terimakasih kepada segenap Dosen dan Staff Karyawan Jurusan Kebidanan Semarang yang telah memberikan 
ilmunya, dukungan, semangat dan kerjasamanya dalam penyusunan naskah publikasi ini

\section{DAFTAR PUSTAKA}

1. Dewi, R., Saleh, I., \& Abduh Ridha. (2017). Related factors with mother behavior immunizing children in the river village regency of kubu raya (the health belief model approach). Jurnal Mahasiswa Dan Penelitian Kesehatan, Vol $4, \quad$ No. https://doi.org/http://dx.doi.org/10.2940 6/jum.v4i2.855.

2. Dinkes Kab. Semarang. (2020). Profil Kesehatan 2019. In Journal of Chemical Information and Modeling (Vol. 53, Issue 9, pp. 1689-1699).

3. Direktur Jenderal Pencegahan dan Pengendalian Penyakit Kemenkes RI. (2020). Buletin Surveilans PD3I \& Imunisasi. 11-11.

4. Dwi Ghunayanti Novianda, \& Mochammad Bagus, Q. (2020). Faktor yang Berhubungan dengan Perilaku Ibu dalam Pemenuhan Imunisasi Dasar. Journal of Health Science and Prevention, 4(2), 125133.https://doi.org/10.29080/jhsp.v4i2.4 02.

5. Islamiyah, K., \& Fatah, M. Z. (2019). Hambatan dan Cues to Action lbu Tidak Memenuhi Imunisasi Campak Bayi (Studi di Desa Grogol, Banyuwangi). Majalah Kesehatan Masyarakat Aceh, 2(3), 131-142. https://ojs.serambimekkah.ac.id/index.p hp/MaKMA/article/view/131-142.

6. Kemenkes RI \&, \& UNICEF. (2020). Imunisasi Rutin pada Anak Selama Pandemi Covid-19 di Indonesia: Persepsi Orang tua dan Pengasuh Agustus 2020.2 1-16. https://www.unicef.org/indonesia/report s/rapid-assessment-immunizationservices-indonesia]\%0Almunisasi.

7. Mulyani, N. . (2013). Imunisasi untuk anak. Nuha Medika.

8. Puri, Y. E., Murti, B., \& Demartoto, A. (2016). Analysis of the Effect of Maternal Perception on Completeness of Child Immunization Status with Health Belief Model. Journal of Health Promotion and Behavior, 01(03), 211222.https://doi.org/10.26911/thejhpb.20 16.01.03.08.

9. Sarwono, S. (2007). Sosiologi Kesehatan. Gajah Mada University Press.

10. Siswanto, E., Margawati, A., \& Suryoputro, A. (2020). Jurnal Litbang: Factors That Influence Immunization Rejection. Jurnal Litbang: Media Informasi Penelitian, Pengembangan Dan IPTEK, 16(1), 1-14. 